\title{
Bone Morphogenetic Proteins, Eye Patterning, and Retinocollicular Map Formation in the Mouse
}

\author{
Daniel T. Plas, ${ }^{1 \star}$ Onkar S. Dhande, ${ }^{4,7 \star}$ Joshua E. Lopez, ${ }^{1}$ Deepa Murali, ${ }^{5}$ Christina Thaller, ${ }^{2,4}$ Mark Henkemeyer, ${ }^{6}$ \\ Yasuhide Furuta, ${ }^{5}$ Paul Overbeek, ${ }^{1,3,4}$ and Michael C. Crair ${ }^{1,4,7}$ \\ Departments of ${ }^{1}$ Neuroscience, ${ }^{2}$ Biochemistry, and ${ }^{3}$ Cell Biology, and ${ }^{4}$ Program in Developmental Biology, Baylor College of Medicine, and ${ }^{5}$ Department of \\ Biochemistry and Molecular Biology, University of Texas, M. D. Anderson Cancer Center, Houston, Texas 77030, ${ }^{6}$ Department of Developmental Biology, \\ University of Texas Southwestern Medical Center, Dallas, Texas 75390, and 'Department of Neurobiology, Yale University School of Medicine, New Haven, \\ Connecticut 06510
}

Patterning events during early eye formation determine retinal cell fate and can dictate the behavior of retinal ganglion cell (RGC) axons as they navigate toward central brain targets. The temporally and spatially regulated expression of bone morphogenetic proteins (BMPs) and their receptors in the retina are thought to play a key role in this process, initiating gene expression cascades that distinguish different regions of the retina, particularly along the dorsoventral axis. Here, we examine the role of BMP and a potential downstream effector, $\mathrm{EphB}$, in retinotopic map formation in the lateral geniculate nucleus (LGN) and superior colliculus (SC). RGC axon behaviors during retinotopic map formation in wild-type mice are compared with those in several strains of mice with engineered defects of BMP and EphB signaling. Normal RGC axon sorting produces axon order in the optic tract that reflects the dorsoventral position of the parent RGCs in the eye. A dramatic consequence of disrupting BMP signaling is a missorting of RGC axons as they exit the optic chiasm. This sorting is not dependent on EphB. When BMP signaling in the developing eye is genetically modified, RGC order in the optic tract and targeting in the LGN and SC are correspondingly disrupted. These experiments show that BMP signaling regulates dorsoventral RGC cell fate, RGC axon behavior in the ascending optic tract, and retinotopic map formation in the LGN and SC through mechanisms that are in part distinct from EphB signaling in the LGN and SC.

Key words: bone morphogenetic proteins; retinotopic map; superior colliculus; lateral geniculate nucleus; visual development; EphB; EphrinB

\section{Introduction}

Early patterning events during eye formation determine subsequent retinal ganglion cell (RGC) axon behavior, which in turn affects the formation of a map of the retina in the optic tectum [superior colliculus (SC)]. In this map, RGC axons lying along the nasotemporal axis of the retina project along the rostrocaudal axis of the SC, whereas axons originating on the dorsoventral axis of the retina project along the mediolateral axis of the SC. Sperry recognized 50 years ago that it was unlikely there were individual molecular labels for each RGC axon, and instead proposed a simple model with two sets of complementary chemical gradients in the retina and optic tectum (Sperry, 1963). Although oversimplified, this "chemoaffinity hypothesis" has contributed substantially toward our understanding of the mechanisms underlying the mapping of the nasotemporal retinal axis, in which complementary gradients of EphA receptor expressed on RGC axons and

\footnotetext{
Received Aug. 18, 2006; revised May 19, 2008; accepted May 24, 2008.

This work was supported by National Institutes of Health Grants R01 MH62639, R01 EY015788, and P30 EY000785 (M.C.C.) and Grant R01 EY017434 (M.H.).

${ }^{*}$ D.T.P. and 0.S.D. contributed equally to this work.

Correspondence should be addressed to Michael C. Crair, Department of Neurobiology, Yale University School of

Medicine, 333 Cedar Street, New Haven, CT 06510. E-mail: michael.crair@yale.edu.

D01:10.1523/JNEUROSCI.3598-06.2008

Copyright $\odot 2008$ Society for Neuroscience $\quad$ 0270-6474/08/287057-11\$15.00/0
}

ephrinA ligands in the tectum play a crucial role in the development of this retinotopic axis (for review, see McLaughlin and O'Leary, 2005; Luo and Flanagan, 2007).

The mechanisms for patterning the dorsoventral retinal axis onto the mediolateral axis of the SC are less well understood (Hindges et al., 2002; Mann et al., 2002; Schmitt et al., 2006; Luo and Flanagan, 2007; Buhusi et al., 2008) and may be quite distinct from those of the nasotemporal retinal axis (Chandrasekaran et al., 2005; Cang et al., 2008). At least two distinct molecular mechanisms appear to contribute to correct dorsoventral mapping. One of these operates within the colliculus itself and biases the direction in which side branches or collaterals on RGC axons form along the mediolateral axis of the colliculus. This behavior depends, in part, on the expression patterns of EphB and Ryk receptors in the retina and EphrinB and Wnt ligands in the tectum (Hindges et al., 2002; Schmitt et al., 2006; Buhusi et al., 2008). The other mechanism is evident within the ascending optic tract and results in sorting of axons within the tract according to their origin along the dorsoventral retinal axis. Although the molecular mechanism of this sorting has not been determined, it occurs as the axons exit the chiasm and is well established by the time the axons reach their central brain target (Simon and O'Leary, 1991; Chan and Guillery, 1994; Plas et al., 2005). The discovery that bone morphogenetic protein 4 (BMP4) is strongly 
expressed only in dorsal retina soon after retinogenesis begins, and that ectopic expression of BMP2, BMP4, or Tbx5, a transcription factor regulated by BMP signaling, causes misexpression of dorsoventral markers and mistargeting of RGC axons along the dorsoventral axis of the retina in the chick provides an important clue about the mechanisms responsible for retinocollicular topography (Furuta and Hogan, 1998; Koshiba-Takeuchi et al., 2000; Sakuta et al., 2006).

BMP signaling has a well known role in dorsoventral midline patterning during embryogenesis (Dale et al., 1997; Graff, 1997) and appears to perform a similar role in specifying the dorsal retina during development. In this report, we explore the role of BMP signaling in the development of topographic maps in the SC and lateral geniculate nucleus (LGN) using several relevant mouse models in which BMP signaling in the eye is disrupted. We also examine the potential role of EphB/ephrinB signaling in pretartget RGC axon behavior. Our results demonstrate that BMP signaling is responsible for the establishment of dorsoventral retinal cell fate, and disrupting this morphogen gradient in the retina correspondingly disrupts pretarget sorting of RGC axons, and the establishment of retinal topography in the LGN and SC.

\section{Materials and Methods}

\section{Animals}

Genotypes of mice used in this study include C57BL/6 wild type (WT) mice, two transgenic lines expressing either human BMP2 (hBMP2) or Xenopus Noggin in the lens of the eye ["BMP-transgenic" (BMP-tg) and "Noggin-transgenic" (Noggin-tg), respectively] on a C57BL/6 background, mice with retina-specific deletion of BMP receptor BMPR1a that were also heterozygote for BMP receptor BMPR1b ("BMP receptor mutant"), and mice with single or double mutations in EphB2 and EphB3 on a CD1 background. The day of birth, which was noted by checking pregnant females every $12 \mathrm{~h}$, was designated as postnatal day $0(\mathrm{P} 0)$.

BMP-tg mice. The BMP-tg mice, generated in the Overbeek Laboratory at Baylor College of Medicine, were homozygous for the BMP2 transgene, and backcrossed eight generations onto the C57BL/6 background and genotyped as described previously (Hung et al., 2002). The BMP transgene was a lens-specific $\alpha \mathrm{A}$-crystallin promoter, which becomes active no later than embryonic day 12.5 (E12.5) (Overbeek et al., 1985), driving expression of hBMP2 cDNA resulting in lens-specific expression [OVE1202A mice in the study by Hung et al. (2002)]. The retina of BMP-transgenics, studied as homozygotes, appears grossly normal at $\mathrm{P} 8$, although their eyes are somewhat smaller than normal (supplemental Fig. $1 B$, available at www.jneurosci.org as supplemental material). Transcription of the BMP2 gene in the transgenic retina was verified by in situ hybridization. In WT eyes at P1, no expression of BMP2 could be detected, as expected, but there was strong expression throughout the lens of the BMP-transgenic embryos at P1 (supplemental Fig. $1 D$, available at www.jneurosci.org as supplemental material).

Noggin-tg mice. Noggin-tg mice, also generated in the Overbeek Laboratory at Baylor College of Medicine, were made using the same lensspecific $\alpha \mathrm{A}$-crystallin promoter to drive the expression of Xenopus Noggin cDNA, and backcrossed eight generations onto the C57BL/6 background and genotyped as described previously (Zhao et al., 2002). Noggin-transgenic mice were used as heterozygotes, because homozygotes had hypertrophic eyes. Heterozygote Noggin-tg mice also had grossly normal retinal lamination at P8, although their eyes are somewhat smaller than WT littermates (supplemental Fig. 1C, available at www.jneurosci.org as supplemental material).

$B M P$ receptor mutant mice. The BMP receptor mutant mice, generated by the Furuta Laboratory at M. D. Anderson Cancer Center, were made using the Six3Cre transgene to drive Cre recombinase to specifically disrupt the expression of BMP receptor 1a (BMPR1a) in the retina. The $\mathrm{BMP}$ receptor mutant mice were made on a null background for BMP receptor $1 \mathrm{~b}$ (BMPR1b). Mice that were null for both BMPR1a and BMPR $1 b$ were anopthalmic. Mice that had one copy of BMPR1b but were null for BMPR1a had grossly normal eye morphology and were used for this study (Murali et al., 2005).

EphB2 and EphB3 mutant mice. EphB2 and EphB3 mutant mice were generated as previously described (Henkemeyer et al., 1996; Orioli et al., 1996). The mice were maintained on a CD1 background, and were examined as either EphB2 ${ }^{+1-} ; \mathrm{EphB}^{-1-}$ (heterozygous for EphB2, homozygous for EphB3) or EphB2 ${ }^{-1-} ; \mathrm{EphB}^{-1-}$ (homozygous for both EphB2 and EphB3).

\section{Retinal labeling}

Pups were anesthetized with an intraperitoneal injection $(0.7 \mathrm{ml} / \mathrm{kg})$ of a combination anesthetic (ketamine, $4.28 \mathrm{mg} / \mathrm{ml}$; xylazine, $0.82 \mathrm{mg} / \mathrm{ml}$; acepromazine, $0.07 \mathrm{mg} / \mathrm{ml}$ ). After surgically opening the eyelid, the eye was protruded and a small injection (2-6 nl) of dye (DiI; Invitrogen; $10 \%$ in dimethylformamide) was made beneath the sclera. The injection was through a glass pipette attached to a nanoinjector (Nanoinject II; Drummond Scientific). Animals were allowed to recover from the anesthesia and were put back with their mother, and then killed after $48 \mathrm{~h}$, or $24 \mathrm{~h}$ for neonatal mice. The injected eye was then fixed in $10 \%$ buffered formalin for later examination to localize the injection site relative to the four major eye muscles [the superior rectus (SR), medial rectus (MR), inferior rectus (IR), and lateral rectus (LR)]. Animals with dye injections that spread beyond a focal spot in the retina were eliminated from additional analysis. The injection position along the perimeter of the retina was reliably localized to a given one-third of each muscle or intermuscle space, yielding 24 possible injection sites. The intermuscle spaces and the spans of the insertion of the four muscles are not equal; they were measured in three P14 animals, and the means are indicated schematically in Figure $2 B$. For the purposes of clarity, we will refer to injections localized to the superior rectus (see Fig. $2 B$, quadrants 1-3) as "dorsal," medial rectus injections as "nasal," lateral rectus as "temporal," and inferior rectus as "ventral."

\section{Distribution of label in whole-mount preparations}

At the time of killing, the brain was removed and the cerebral cortex was dissected away. Digital images of dye label were acquired under epifluorescent illumination using a CCD camera and associated software (Epix). The superior colliculus was first imaged using a $2.5 \times$ objective. The focus was then shifted to the anterior edge of the superior colliculus and again imaged at $2.5 \times$ to assess the distribution of axons as they passed into the $\mathrm{SC}$ from the brachium [brachium of the SC (bSC)] (see Fig. 2A).

After the superior colliculus and brachium were digitally imaged, the brain was bisected midsagittally and the one-half contralateral to the injected eye was oriented with the lateral side up so that the uppermost part of the optic tract could be visualized. This is the region just before the tract reaches the ventral lateral geniculate nucleus and is referred to here as the delta of the optic tract (dOT) (see Fig. $2 \mathrm{~A}$ ). Fluorescent digital images of the dOT were obtained using a $5 \times$ objective.

We quantified the axon distribution in the dOT and bSC using software written in IDL (Research Systems) and Matlab. First, a path was defined crossing the tract from the medial to the lateral edge. The fluorescence of the pixels in this path was weakly smoothed with a Gaussian filter and recorded as a fluorescence profile (FP), which gives the filtered fluorescence as a function of mediolateral position in the tract. The FP was background subtracted and normalized by the total area under the FP curve. The position of labeled retinal axons in the tract was quantified by calculating the center of mass of fluorescent label along the defined mediolateral path. A center of mass value of $0 \%$ indicates that all axons lie on the medial edge of the tract, and a value of $100 \%$ indicates that all axons lie on the lateral edge of the tract.

All results are reported as means \pm SEM. Error bars in figures represent SEM. Means are compared with Student's $t$ test and corrected for multiple comparisons where appropriate. Results are considered significant at the $p=0.05$ level.

\section{In situ hybridization}

Tissue preparation, automated in situ hybridization (ISH), and digital imaging were performed as previously described (Carson et al., 2002; Visel et al., 2004; Yaylaoglu et al., 2005) and as described online at http:// www.genepaint.org/RNA.htm. Briefly, coronal serial sections of heads of 


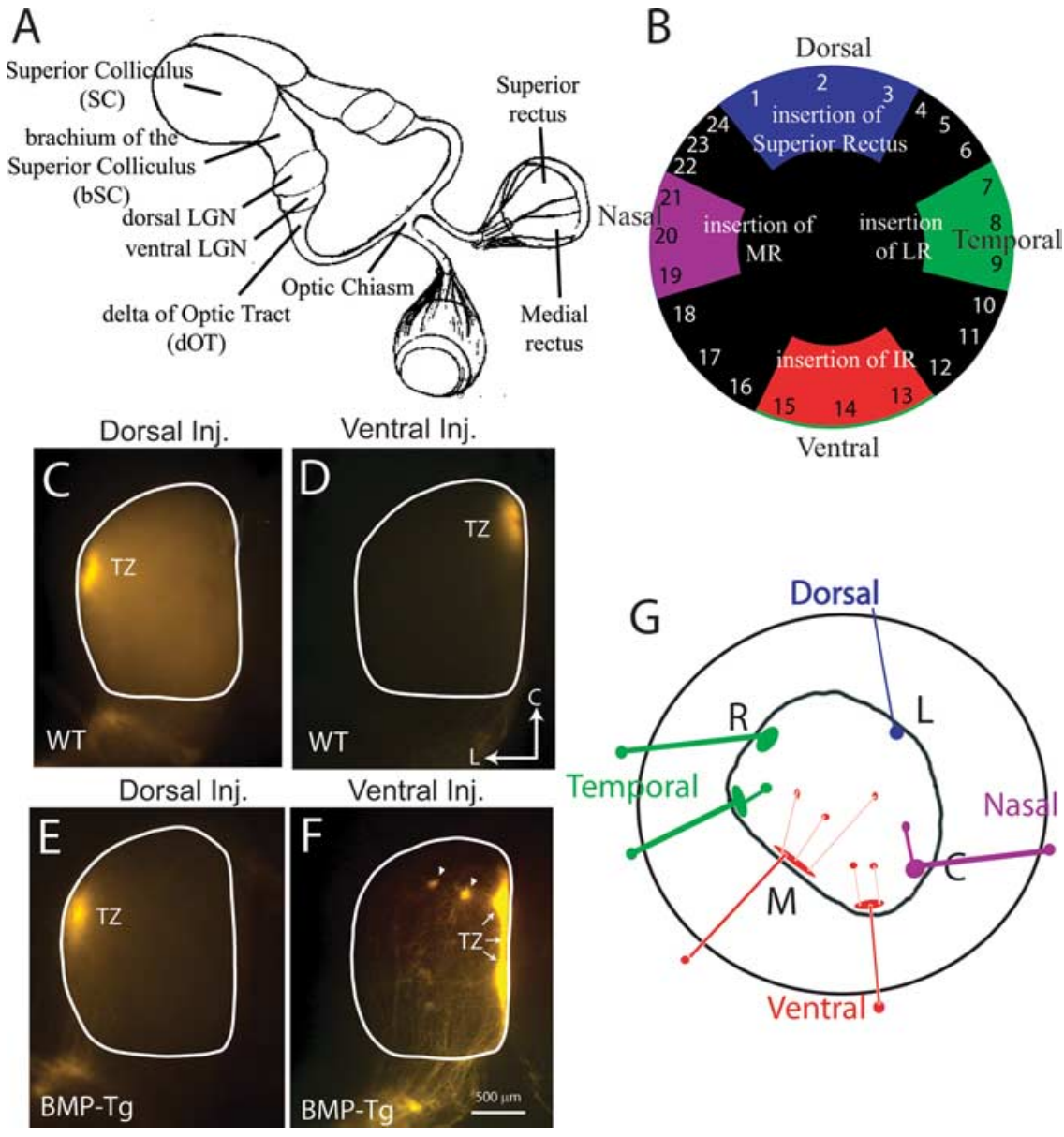

Figure 1. Projections from ventral, but not dorsal, retina are inappropriate in BMP transgenic mice at P8. $A$, Schematic of mouse visual system, showing the major retinal projections, including the dorsal and ventral LGN and the SC. The accessory optic system is not shown. The delta of the optic tract is the area of the ascending optic tract before it enters the ventral LGN. The brachium of the superior colliculus is the area of the optic tract between the LGN and SC, just before the ganglion cell axons enter the $S C$. $B$, The retina is assigned coordinates based on the insertion of the four major occulomotor muscles, namely the $S R$, IR, $L R$, and MR (Plas et al., 2005). C, A focal injection into dorsal retina of a WT mouse labels a target zone (TZ) in lateral SC. D, A focal injection into ventral retina of a WT mouse labels a TZ in medial SC. L, Lateral; $C$, caudal. $\boldsymbol{E}$, In BMP transgenic mice, the projection from dorsal retina is similar to that in WT mice and topographically correct. $\boldsymbol{F}$, Projections from ventral retina in BMP transgenic mice show "ectopic spots" (arrows) lateral to the expected TZ. G, Summary diagram depicting graphically the frequency of inappropriate projections to the $S C$ as a function of the position of the retinal dye injection in the BMP transgenic mouse. Dorsal retinal injections lead to normal collicular projections to lateral $(\mathrm{L})$ colliculus (blue). Ventral retinal injections lead to a medial target zone (M) in colliculus and many ectopic spots (red). Temporal (green) and nasal (purple) retinal injections are mostly normal, with some cases of inappropriate projections to the colliculus. R, Rostral; L, lateral; M, medial; C, caudal.

tions, we made small, focal injections of DiI into the retina and identified the location of the injections around the perimeter of the retina relative to the four principal extraocular muscles, as described previously (Fig. $1 B$ ) (Plas et al., 2005). This "muscle coordinate system" permitted us to confidently examine RGC axon origin regardless of age or size of the eye.

Injections of DiI were made in P6 BMP-tg mice and compared with WT mice injected at the same age. Labeled projections in the SC were analyzed on P8, an age when retinotopic projections are anatomically mature (Simon and O'Leary, 1992a). In general, injections into dorsal retina of BMP-tg mice produced normal projection patterns without ectopic spots ( 1 of 14 dorsal injections had ectopic spots) (Fig. 1E, Table 1). In contrast, ventral injections in the BMP-tg mice usually produced a normal target zone with multiple ectopic projections ( 11 of 14 cases) (Fig. $1 F$, Table 1 ). Ectopic spots, which are never seen in WT mice (Fig. $1 C, D$ ), are caused by nearby RGC axons projecting to inappropriate targets in the SC. At retinal locations intermediate between dorsal and ventral, such as nasal or temporal locations, there was a graded tendency to form ectopic projections, suggesting that BMP also has weak effects on targeting of RGC axons along the nasotemporal axis (summarized schematically in Fig. $1 G$; quantified in Table 1).

\section{Mediolateral entry of ventral axons into $\mathrm{SC}$ is abnormal in BMP-transgenic mice} In WT mice, axons that terminate in a given target zone enter the superior colliculus approximately aligned with the mediolateral position of the target zone (Plas et al., 2005). For example, axons from ventral retina enter the SC on the medial side of the brachium and will terminate in medial SC (Fig. $2 A)$. In general, the degree of alignment of the incoming axons with the target zone is greater when the target zone is on the lateral

P1 WT, BMP-tg, and Noggin-tg mice were cut with a cryostat. After paraformaldehyde fixation and acetylation, the slides were assembled into flow-through hybridization chambers and placed in a Tecan Genesis 200 liquid-handling robot. Templates for synthesis of digoxygeninlabeled riboprobes for EphB2, efnB2, and $h B M P 2$ have been described previously (Chapman et al., 1996; Birgbauer et al., 2000; Barbieri et al., 2002). Hybridized antisense probes were detected by catalyzed reporter deposition using biotinylated tyramide followed by colorimetric detection of biotin with avidin coupled to alkaline phosphatase (Carson et al., 2005; Yaylaoglu et al., 2005).

\section{Results}

Retinotopic projections from ventral retina are disrupted in BMP-transgenic mice

Retinal ganglion cell axons of the mouse project primarily to the contralateral brain, where they form retinotopic maps in the ventral and dorsal divisions of the lateral geniculate nucleus and in the superior colliculus (Fig. 1A). To study the retinotopic projec- or medial edge of the SC, that is, when the axons originate in extreme dorsal or ventral retina.

The pattern of ventrally labeled axons is distinctly different for BMP-tg mice (Fig. $2 \mathrm{~B}$ ) where "off-target" axons are observed at the point of entry into SC. We quantified this targeting defect by examining the distribution of fluorescence across the width of the brachium of the SC, with example florescence profiles shown in Figure $2 C$. The center of mass of the axon distribution from ventral RGC axons (Fig. 2C, red) for a population of WT and BMP-transgenic mice in the brachium of the SC quantitatively confirms that WT axons are typically arrayed medially (Fig. 2D) (center of mass at $28 \pm 8 \% ; n=5$ ), whereas axons from BMP-tg mice show no positional bias (Fig. 2D) (center of mass at $47 \pm$ $7 \% ; n=10 ; p<0.001)$.

In contrast, injections into dorsal retina resulted in similar axon distributions in WT and BMP-tg mice. For example, axons 
Table 1. Summary of retinal injections in BMP-transgenic mice

\begin{tabular}{lll}
\hline Retinal location & $\begin{array}{l}\text { Fraction of animals } \\
\text { with ectopic spots }\end{array}$ & $\begin{array}{l}\text { Fraction with abnormal (stray } \\
\text { axons and/or spots) projections }\end{array}$ \\
\hline Dorsal & $1 / 14$ & $1 / 14$ \\
Dorsal-temporal & 0 & 0 \\
Temporal & $2 / 5$ & $2 / 5$ \\
Ventral-temporal & $2 / 7$ & $5 / 7$ \\
Ventral & $10 / 13$ & $11 / 13$ \\
Ventral-nasal & $1 / 6$ & $2 / 6$ \\
Nasal & $1 / 3$ & $2 / 3$ \\
Dorsal-nasal & $1 / 6$ & $1 / 6$ \\
\hline
\end{tabular}
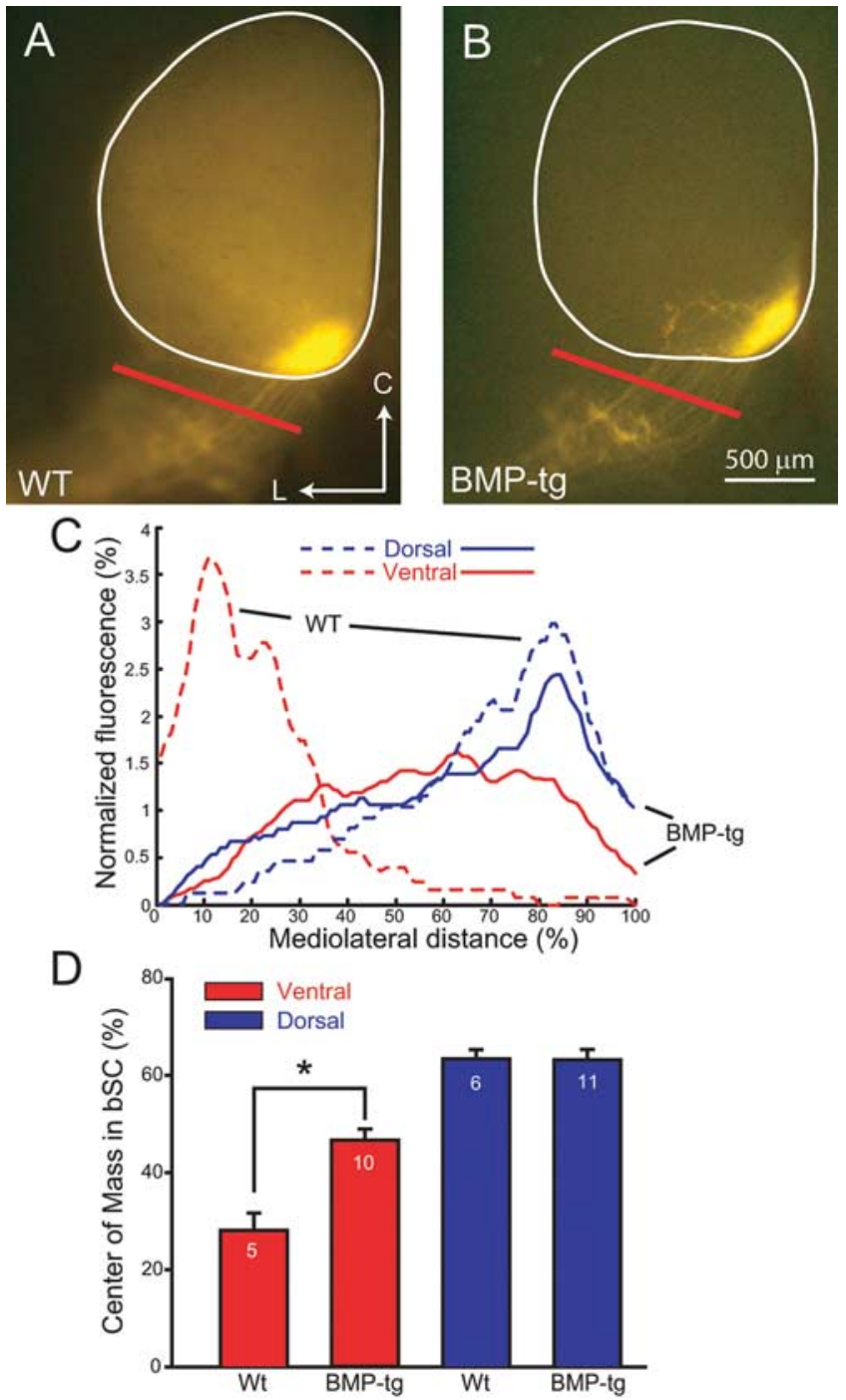

Figure 2. Ventral retinal axons in BMP transgenics are misplaced in the bSC at P8. A, Axons originating in ventral retina of WT mice enter the SC from the medial edge of the bSC in WT mice. L, Lateral; C, caudal. B, In BMP-transgenic mice, ventral axons lose their confinement and spread laterally in the bSC. $C$, The difference in the distribution of RGC axons from ventral (red) retina in the bSC is shown as normalized fluorescence across the width of the bSC ( $A, B$, red bars) for representative examples of WT (dashed lines) and BMP-transgenic mice (solid lines). The axon distributions in the bSC resulting from dorsal (blue) injections are similar in the two genotypes. $\boldsymbol{D}$, These results are summarized as the mean position of the center of mass of the fluorescent distribution of labeled RGC axons from ventral (red) or dorsal (blue) injections across the width of the bSC, with the number of animals indicated in each bar. The mean centers of mass for the ventral retinal injections retina are significantly different between the two genotypes $\left({ }^{*} p<0.001\right)$. Error bars indicate SEM.

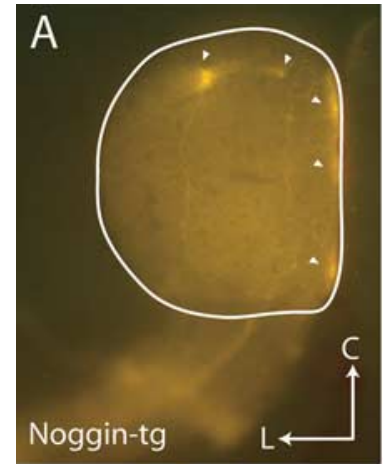

Dorsal axons
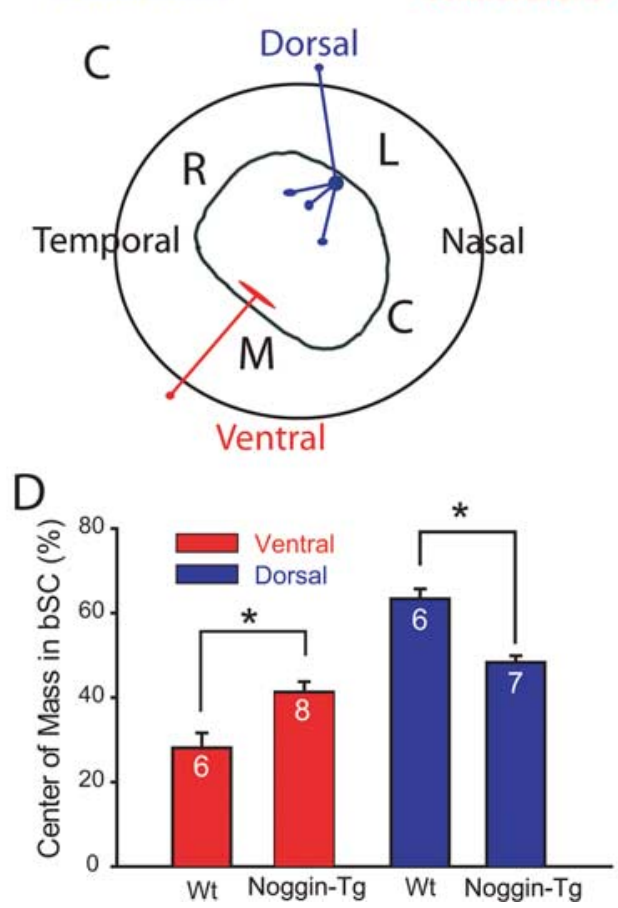

Figure 3. Dorsal retinal axons in Noggin-transgenic mice are misplaced in the bSC at P8. $A$, Example of a dorsal retinal injection in a Noggin transgenic leading to multiple ectopic spots (arrowheads) at inappropriate locations in the SC. L, Lateral; C, caudal. B, Ventral retinal injections nearly always terminate normally in the SC. C, Summary diagram showing that dorsal injections lead to misprojections in Noggin transgenics, but ventral retinal injections are relatively normal. R, Rostral; L, lateral; M, medial; C, caudal. D, Summary quantification showing that the distribution of RGC axons in the bSC in Noggin transgenics is completely disturbed for dorsal injections (blue) and partially disturbed for ventral injections (red), so that dorsal ( ${ }^{*} p<$ $0.0001)$ and ventral ( $\left.{ }^{*} p<0.01\right)$ axons in Noggin transgenics are less confined to the lateral and medial sides of the bSC, respectively, than in WT mice. Error bars indicate SEM.

from dorsal injections were distributed in the lateral brachium in both BMP-tg and WT mice (Fig. 2C, blue). Summary quantification using the center of mass of the fluorescence label in the brachium again confirms this qualitative point, with no difference in the distribution of dorsal axons in BMP-tg and WT mice (Fig. 2D) (BMP-transgenic center of mass, $63 \pm 5 \%$; $n=11$; WT center of mass, $63 \pm 7 \% ; n=6 ; p=0.954)$. Thus, dorsal axons in BMP-tg mice project normally to the SC, but the trajectory of ventral axons is severely disturbed. This suggests that graded BMP signaling acts as a dorsalizing factor in the developing retina and confirms that the dorsoventral identity of axons is partially reflected in the position of axons before they enter the SC at the brachium. 
Table 2. Summary of retinal injections in Noggin-transgenic mice

\begin{tabular}{ll}
\hline Retinal location & $\begin{array}{l}\text { Fraction of animals with ectopic projections } \\
\text { (stray axons and/or spots) }\end{array}$ \\
\hline Dorsal & $8 / 8$ \\
Dorsal-temporal & $1 / 1$ \\
Temporal & $2 / 2$ \\
Ventral-temporal & 0 \\
Ventral & $1 / 11$ \\
Ventral-nasal & $0 / 1$ \\
Nasal & 0 \\
Dorsal-nasal & $1 / 1$ \\
\hline
\end{tabular}

Projection and sorting defects in Noggin-transgenic mice Noggin is a BMP antagonist that inhibits BMP signaling by blocking the binding of the BMP ligand to both types of BMP receptors (De Robertis and Kuroda, 2004). In Noggin-tg mice, which secrete Noggin from the lens, we hypothesize that the suppression of BMP signaling caused by high levels of Noggin in the eye will interfere with the specification of dorsal retinal cell fate by endogenous BMP. Indeed, topographic projections from the retina to the colliculus are disrupted in Noggin-tg mice, with targeting of dorsal RGC axons most severely disturbed (Fig. $3 A$ ), and only the projections from the most ventral part of retina remain mostly undisturbed (Fig. $3 B$ ). Specifically, all injections into the dorsal retina resulted in mistargeted axons in the SC ( 8 of 8 cases had ectopic spots) (Table 2$)$, whereas injections into ventral retina rarely resulted in ectopic spots ( 1 of 11 cases) (Table 2) (summarized schematically in Fig. $3 C$ ). The dorsal injections in Noggin-tg mice also showed evidence of nasotemporal targeting errors (Fig. $3 A$ ). Moreover, the few cases in which the injections were localized to nasal or temporal retina often, although not always, showed misprojections (Table 2), suggesting that BMP signaling also impacts nasotemporal targeting.

The mediolateral distribution of axons entering the SC at the brachium is also altered in the Noggin-tg mice, with axons from the dorsal retina most severely disturbed (Fig. 3D). Summary quantification using the center of mass of the fluorescence label in the brachium shows that dorsal RGC axons from Noggin-tg mice are pushed into the midbrachium (Noggin-tg centers of mass at $48.3 \pm 4.2 \%, n=7$; WT center of mass at $63.3 \pm 4.7 \%$, $n=6 ; p<0.0001)$. RGC axons from the ventral retina in Noggin-tg mice are also somewhat disturbed (Noggin-tg centers of mass at $41.3 \pm 7.0 \%, n=8$; WT center of mass at $28.1 \pm 7.9 \%$, $n=6 ; p<0.01$ ), although not as severely as dorsal axons. Thus, the sorting of dorsal axons in Noggin-tg mice as they enter the SC, as well as their targeting in the SC, is completely compromised. The sorting of ventral RGC axons in Noggin-tg is partially disturbed, and the targeting of ventral axons in the SC is nearly normal. This is consistent with a model in which the high dorsal expression of BMP in the developing eye helps specify dorsal retinal ganglion cell fate, and interfering with this signaling with transgenic expression of Noggin, a BMP antagonist, has its greatest effect on dorsal axons. Similarly, overwhelming the endogenous dorsoventral gradient of BMP in BMP-tg mice interferes especially with ventral axons, has weaker effects on nasal and temporal axons, but leaves the projection from dorsal axons intact. Furthermore, dorsoventral axon sorting errors in the bSC are typically associated with mistargeting in the SC itself.

\section{Mediolateral axon sorting in the optic tract is disrupted in BMP-tg and Noggin-tg mice}

The SC is the final target of retinal ganglion cell axons. By the time the axons have reached this point, they have already traversed the ventral and dorsal divisions of the LGN of the thalamus, where they also form retinotopic maps. We investigated in P8 mice whether the disruption of mediolateral axon order in BMP- and Noggin-tg mice is evident in the optic tract, at a point before the axons have not even reached their first topographic target. We measured axon sorting in the optic tract just before its entry into the ventral LGN, which we refer to as the dOT (Fig. $1 A$ ). In WT mice, axons from ventral and dorsal retina are clearly sorted in the medial and lateral parts of the optic tract (dOT), respectively (Fig. 4A, B). Axons at the dOT from dorsal retina in BMP-tg are also quite lateralized (Fig. $4 F$ ), as in WT mice. In contrast, axons from ventral retina at the dOT in BMP-tg mice are broadly distributed without any apparent sorting (Fig. 4E). In Noggin-tg mice, sorting of axons from the dorsal retina is completely disturbed (Fig. 4C), and the sorting of axons from the ventral retina is relatively intact (Fig. 4C). Quantification of this sorting was again performed by calculating the center of mass of the fluorescent distribution of label at the dOT across its mediolateral width for dorsal and ventral retinal injections (Fig. 4G). This quantification reveals that ventral RGC axons in BMP-tg mice and dorsal RGC axons in Noggin-tg mice are completely missorted in the dOT (WT ventral injection center of mass, $24 \pm 1 \%, n=2$; WT dorsal center of mass, $69 \pm 5 \%, n=3$; Noggin-tg ventral injection center of mass, $38 \pm 2 \%, n=6$; Noggin-tg dorsal center of mass, $53 \pm 2 \%, n=7$; BMP-tg ventral injection center of mass, $55 \pm 2 \%, n=10$; BMP-tg dorsal center of mass, $69 \pm 3 \%, n=11$; $p<0.01$ for difference between WT and BMP-tg ventral injections and WT and Noggin-tg dorsal injections. All other comparisons with WT are not statistically significant).

\section{Aberrant sorting of axons in the optic tract is evident before target formation in the SC}

By P1, nearly all RGC axons have entered the colliculus, although no target zone is yet established. At this early age, RGC axons from all parts of the retina extend nearly the entire length of the colliculus, and axon branching is still quite minimal (Hindges et al., 2002). We examined the sorting of axons in BMP-transgenic mice at P1 to determine whether RGC axon-target interactions were somehow responsible for the disruption in sorting in the optic tract at later ages. Instead, we found that, even at P1, axons from ventral retina in BMP-tg mice (Fig. 5B) are not at all confined to the medial optic tract, as they are in WT mice (Fig. $5 A$ ). Quantification of the distribution of axons in the optic tract at P1 confirms this qualitative impression (Fig. 5C) (center of mass for BMP-tg is $56 \pm 4 \%, n=5$; center of mass for WT is $31 \pm 1 \%, n=$ $11 ; p \ll 0.001)$. Given these data, it is difficult to argue that axon-target interactions are responsible for the severe disruption in sorting seen in the ascending optic tract at these early ages.

\section{Off-target axons mature into ectopic spots in the SC}

During normal development, a small number of retinal axons enter the SC at inappropriate mediolateral positions (Fig. 6A, white arrows), but by maturity, most of these missorted axons are eliminated (Simon and O'Leary, 1992a,b). Target zones begin to emerge at $\mathrm{P} 3$ at a mediolateral position in SC that corresponds to the mediolateral location of the peak density of incoming axons from the brachium (Fig. $6 \mathrm{~A}$, red arrows). In the BMP-transgenic mice at P3 (Fig. 6B, C), axons labeled by ventral retinal injections are much more widespread in the brachium, and numerous axons enter the SC at incorrect mediolateral locations. In the SC, these missorted axons form dense branching networks visible even at off-target locations (Fig. 6C).

Although it is often difficult to visualize the individual axons 
that give rise to ectopic spots at $\mathrm{P} 8$, because the axons are not superficial, we see clear evidence that ectopic spots result from axons that have entered the anterior edge of the SC at an inappropriate mediolateral location (Fig. $6 D, E$ ). In these cases, just as in the wild-type mice, the entry point and final arborization of the axons are aligned, albeit at a mediolaterally inappropriate position.

\section{Topography of LGN map is also} disturbed in BMP-transgenic mice Retinal axons form topographic termination patterns in the ventral lateral geniculate nucleus (vLGN) and the dorsal lateral geniculate nucleus (dLGN) as well as the superior colliculus. We wondered whether the retinotopic maps in LGN were also disrupted by the transgenic overexpression of BMP2. Indeed, this was typically the case (Fig. 7). The LGN is much more compact in the rodent than the SC, so it is more difficult to quantitatively characterize targeting errors in the LGN. Nonetheless, it was clear that the normally predictable patterns of label in the LGN of WT mice resulting from focal injection into ventral retina were profoundly perturbed in the LGN of BMP-tg mice. For example, targeted injections into ventral retina in BMP-tg mice, which typically lead to ectopic spots in the superior colliculus (Fig. $7 A, B$ ), cause corresponding ectopic spots in the same mice in dorsal and ventral LGN (Fig. 7C,D). This suggests that common mechanisms are responsible for retinotopic map development in the lateral geniculate nucleus and superior colliculus.

\section{Pretarget sorting in BMP receptor mutants is similar to that in Noggin-tg mice}

We examined the projections from dorsal retina in mice lacking one or both copies of the BMP receptors BMPR1a and BMPR1b. BMPR1a is expressed ubiquitously, whereas BMPR1b has a ventral-high to dorsal-low gradient of expression in the developing retina (Furuta and Hogan, 1998). Loss of both of these receptors entirely prevents the development of the eye, whereas loss of both copies of either receptor alone or one copy of both receptors has no detectable effect on retinotectal topography (Murali et al., 2005) (Fig. 8A, "control mice"). Mice homozygous for BMPR1a and heterozygous for BMPR1b (BMP receptor mutant mice) have eyes with normal structure but a strong disruption of topography from dorsal retina (Fig. $8 \mathrm{~B}$ ), quite reminiscent of the pattern of ectopic spots in Noggin-tg mice. We examined whether this targeting defect is accompanied by a failure of pretarget sorting in the optic tract. In control mice, sorting in the optic tract for dorsal retinal injections was normal (Fig. 8C,E), whereas in BMP receptor mutant mice, which have targeting defects in the colliculus for dorsal retinal axons, sorting in the optic tract was also disturbed (Fig. 8D,E) (center of mass for BMP receptor mutant is $39 \pm 2 \%, n=3$; center of mass for control mice is $69 \pm 1 \%, n=16 ; p \ll 0.001)$.

\section{Role of EphB/ephrinB signaling in pretarget sorting}

Retinal axon behavior that differs depending on the dorsal or ventral retinal origin of the axon presumably is the result of differential patterns of gene expression in the retina. For example, EphB receptors and their ligands, which are thought to mediate aspects of axon branching along the mediolateral axis of the SC, have expression patterns that vary with position along the dorsoventral axis during embryonic development (Henkemeyer et al., 1996; Braisted et al., 1997; Birgbauer et al., 2000; Hindges et al., 2002; Mann et al., 2002; McLaughlin et al., 2003). We investigated whether the early spatial patterns of BMP expression are responsible for subsequent patterns of gene expression of members of the EphB/ephrinB receptor-ligand system consistent with their role in mediolateral targeting in the SC. Using ISH, we visualized the expression pattern of EphB2 and ephrinB2 in the retina of $\mathrm{P} 1$ WT, BMP-tg, and Noggin-tg mice (Fig. 9). In WT mice, ephrinB2 

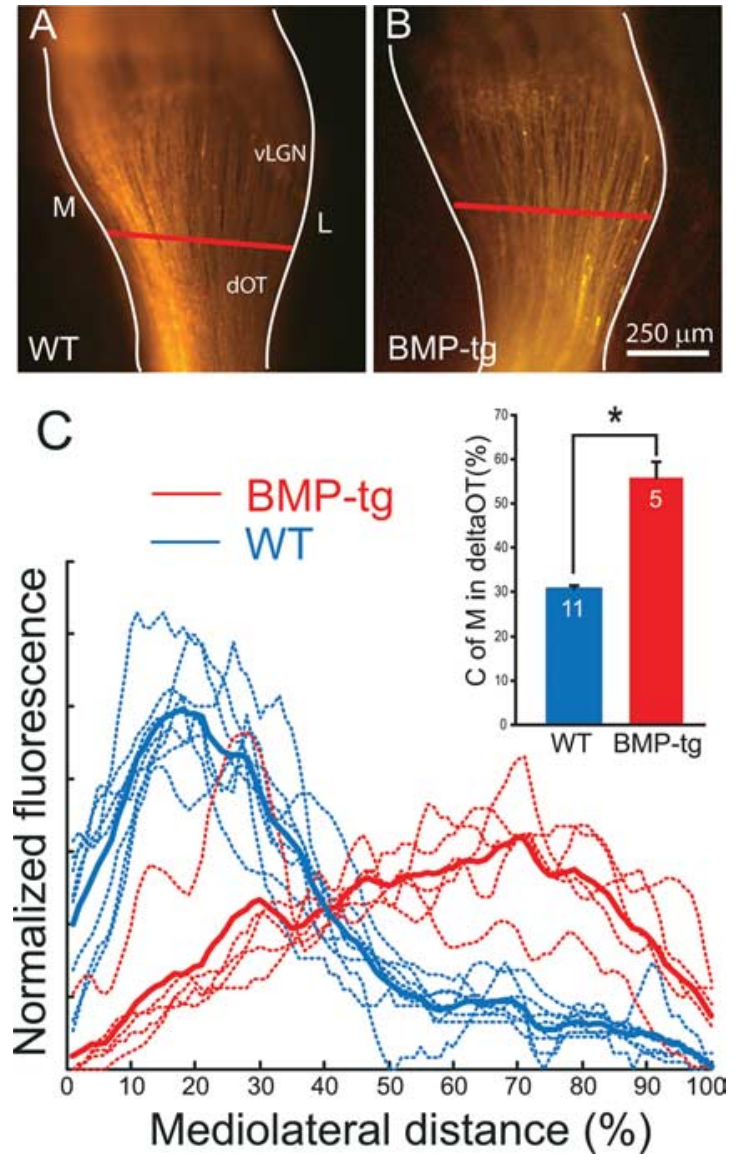

Figure 5. Axon sorting even at $P 1$ is disturbed in BMP-transgenic mice. $A, B, A x$ on label from ventral retina is segregated to medial (M) optic tract by P1 in WT mice but already extends into lateral (L) optic tract in BMP transgenics at P1. C, The distribution of ventral label in the optic tracts of the two genotypes is quite different (BMP-transgenic is red; WT is blue; the dashed lines are example fluorescent profiles, and the solid lines are average fluorescent profiles). Each curve corresponds to the distribution of fluorescent label across the d0T $(A, B$, red bar) in one animal. Note that the fluorescent profiles for ventral retinal axons in BMP-transgenic mice (red) are not sorted to the medial optic tract, as they are in WT mice (blue). Summary quantification (inset) for the center of mass of fluorescent label in the d0T in P1 WT (blue; $n=11$ ) and BMP-transgenic (red; $n=5 ;{ }^{*} p \ll 0.001$ ) mice. Error bars indicate SEM.

has a high-dorsal to low-ventral pattern of expression, and EphB2 has a high-ventral to low-dorsal pattern of expression, consistent with what was previously observed (Henkemeyer et al., 1996; Birgbauer et al., 2000; Hindges et al., 2002; Murali et al., 2005). In BMP-tg mice, the expression of ephrinB2 appears unaltered, but the expression of EphB2 is reduced and the high-ventral to lowdorsal gradient is absent (Fig. 9B,E). In Noggin-tg mice, the expression of ephrinB2 is suppressed, and the graded expression of EphB2 is lost, although overall expression levels appear intact (Fig. 9C,F). This is consistent with results from BMP receptor mutants, in which ephrinB2 expression in the retina was also found to be completely suppressed and the graded expression of EphB2 was absent (Murali et al., 2005). These results show that BMP signaling regulates the dorsoventral expression pattern of axon guidance factors (EphB2/ephrinB2) that are known to play a role in RGC axon branching and collicular target formation in the SC. Because EphB/ephrinB signaling has been specifically implicated in mapping of the dorsoventral axis of the retina onto the colliculus, we examined RGC axon behavior in EphB2/B3 mutant mice to determine whether EphB/ephrinB signaling also plays a role in pretarget sorting. Consistent with previous reports
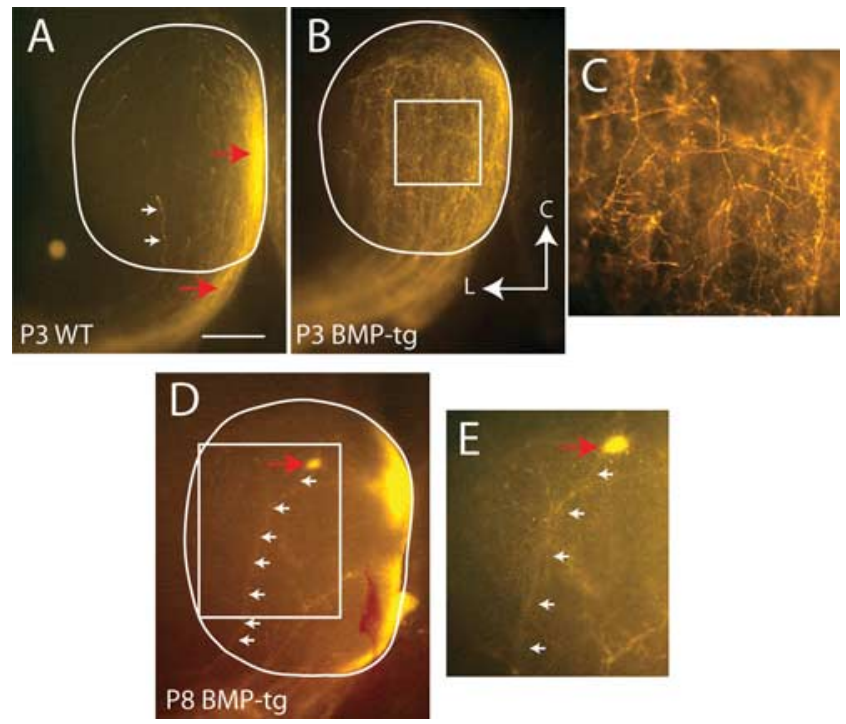

Figure 6. Mistargeted axons persist in BMP transgenics. $\boldsymbol{A}$, In WT mice at $\mathrm{P} 3$, nearly all retinal axons have invaded the $S C$, but the target zone has not been elaborated. Axons from ventral retina in WT mice enter the anterior $\mathrm{SC}$ at its medial edge (bottom red arrow) and are clearly confined to medial SC (top red arrow). Very few axons are in off-target regions (white arrows). $\boldsymbol{B}$, In BMP-transgenic mice at P3, axons from ventral retina are diffusely spread across the mediolateral extent of the $\mathrm{SC}$, with many off-target RGC axons forming branches at inappropriate locations in the SC. $\boldsymbol{C}$, High-magnification ( $10 \times$ ) image of white boxed region in $\boldsymbol{B}$ shows an off-target area in which a dense network of branching axons is evident. This dense network of off-target axons does not exist in WT mice. D, At P8 in BMP transgenics, some ventral RGC axons that entered the SC lateral (small white arrows) to their normal trajectory in bSC maintain a misprojection to ectopic spots (large red arrow) lateral to their normal target zone in medial SC. $\boldsymbol{E}$, High-magnification $(10 \times)$ image of white boxed region in $\boldsymbol{D}$ shows the misprojecting ventral axons in BMP-transgenic mice that enter the $\mathrm{SC}$ from lateral locations often form ectopic spots (red arrow) in the SC. Lateral (L) and caudal (C) designation in $B$ applies to all panels. Scale bar: (in A) $A, B, D, 500 \mu \mathrm{m} ; C, E, 100 \mu \mathrm{m}$.

(Hindges et al., 2002), we frequently observed ectopic target zones in SC projections from EphB2/B3 null ventral RGC axons $\left(\mathrm{EphB} 2^{+/-} ; \mathrm{B} 3^{-1-}, 1\right.$ of $6 ; \mathrm{EphB}^{-/-} ; \mathrm{B} 3^{-/-}, 6$ of 12 mice). However, pretarget sorting in the brachium of the $\mathrm{SC}$ was not impaired in EphB2/B3 mutants [center of mass for control mice, $40 \pm 1 \%, n=11$; center of mass for EphB2 ${ }^{+/-} ; \mathrm{B} 3^{-/-}, 35 \pm 3 \%$, $n=6$; center of mass for EphB2 ${ }^{-1-} ; \mathrm{B} 3^{-1-}$ mice, $32 \pm 1 \%, n=$ 12 ; sorting is slightly better (smaller center of mass) in EphB2 ${ }^{-1}$ $-; \mathrm{B} 3^{-1-}$ mice than in control mice; $p<0.01$ ], implying that a mechanism apart from $\mathrm{EphB} / \mathrm{ephrinB}$ signaling is principally responsible for this axon guidance behavior in the ascending optic tract (Fig. 9G-J).

\section{Discussion}

We used several different lines of knock-out and transgenic mice to establish and clarify the role of BMP signaling in retinotopic map formation and pretarget sorting in the developing retinofugal pathway of the rodent. In BMP-tg and Noggin-tg mice, SC target formation and pretarget sorting of ventral and dorsal axons, respectively, were dramatically disturbed. In BMP receptor mutant mice, pretarget sorting of dorsal but not ventral axons was disrupted. We also found that dorsoventral targeting errors in the SC and LGN of these transgenics are always associated with sorting errors in the ascending optic tract, suggesting a mechanistic link. Finally, we showed that RGC axon pretarget sorting was undisturbed in EphB2/B3 mutant mice. Together, these data demonstrate that BMP signaling patterns the dorsoventral axis of the retina and influences RGC axon guidance behavior in the 

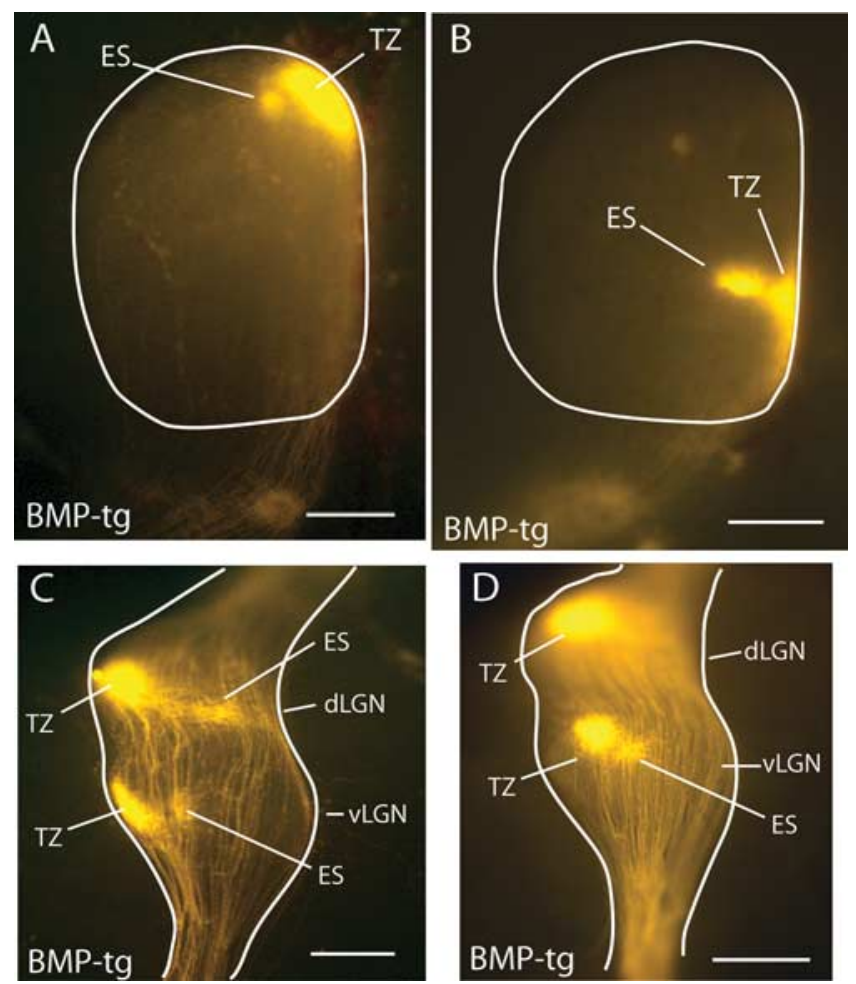

Figure 7. The LGN in BMP-transgenic mice contains axons that are mistargeted in a manner similar to that seen in the SC. $A, B$, In P8 BMP-transgenic mice, ventral axons often form ectopic spots (ES) lateral to the normal target zone (TZ). C, D, The dorsal and lateral subdivisions of the LGN each contain a retinotopic representation of the retina that is formed by the retinal axons as they pass through these structures on their way to the SC, making topographic appropriate synaptic connections via axon collaterals. In the BMP-transgenic mice, the disturbance of topography in the projection from ventral retina seen in the $S C(A, B)$ is frequently accompanied by similar disruptions of retinotopy in the $\operatorname{LGN}(\boldsymbol{C}, \boldsymbol{D})$. Scale bars: $\boldsymbol{A}, \boldsymbol{B}, 500 \mu \mathrm{m} ; \boldsymbol{C}, \boldsymbol{D}, 250 \mu \mathrm{m}$.

ascending optic tract through a mechanism that is, at least in part, independent of EphB/ephrinB signaling.

\section{Dorsoventral topography depends on BMP signaling}

We demonstrated that transgenic induction of high levels of BMP throughout the developing eye leads ventral axons to mistarget in the LGN and SC. The targeting of dorsal axons, in contrast, is not disturbed in BMP-tg mice. Given the endogenous high-dorsal to low-ventral expression of BMP in vertebrates, we conclude that the establishment of dorsoventral topography depends on BMP signaling, with high levels of BMP leading to dorsal cell fate, and low levels to ventral cell fate. This model is reinforced by results from the Noggin-tg mice, which have an opposite phenotype to that of the BMP-tg, with relatively normal targeting of ventral RGC axons and grossly abnormal targeting and sorting of dorsal RGC axons. This is an expected phenotype, given that Noggin binds to endogenous BMP and prevents it from activating the BMP receptor. Finally, eye-specific BMP receptor mutant mice have a similar targeting phenotype as the Noggin-tg mice, reinforcing the hypothesis that activation of the BMP receptor is necessary to establish dorsal cell fate in the developing retina.

The high-ventral to low-dorsal expression pattern of EphB2 receptor in the retina is thought to play an important role in the development of retinotopy in the SC and LGN (Hindges et al., 2002; Mann et al., 2002). In BMP-tg mice, ephrinB2 expression in the retina is intact, but the graded expression of EphB2 is disturbed. In Noggin-tg, ephrinB2 expression is dramatically reduced, and the high-ventral to low-dorsal expression of EphB2 is
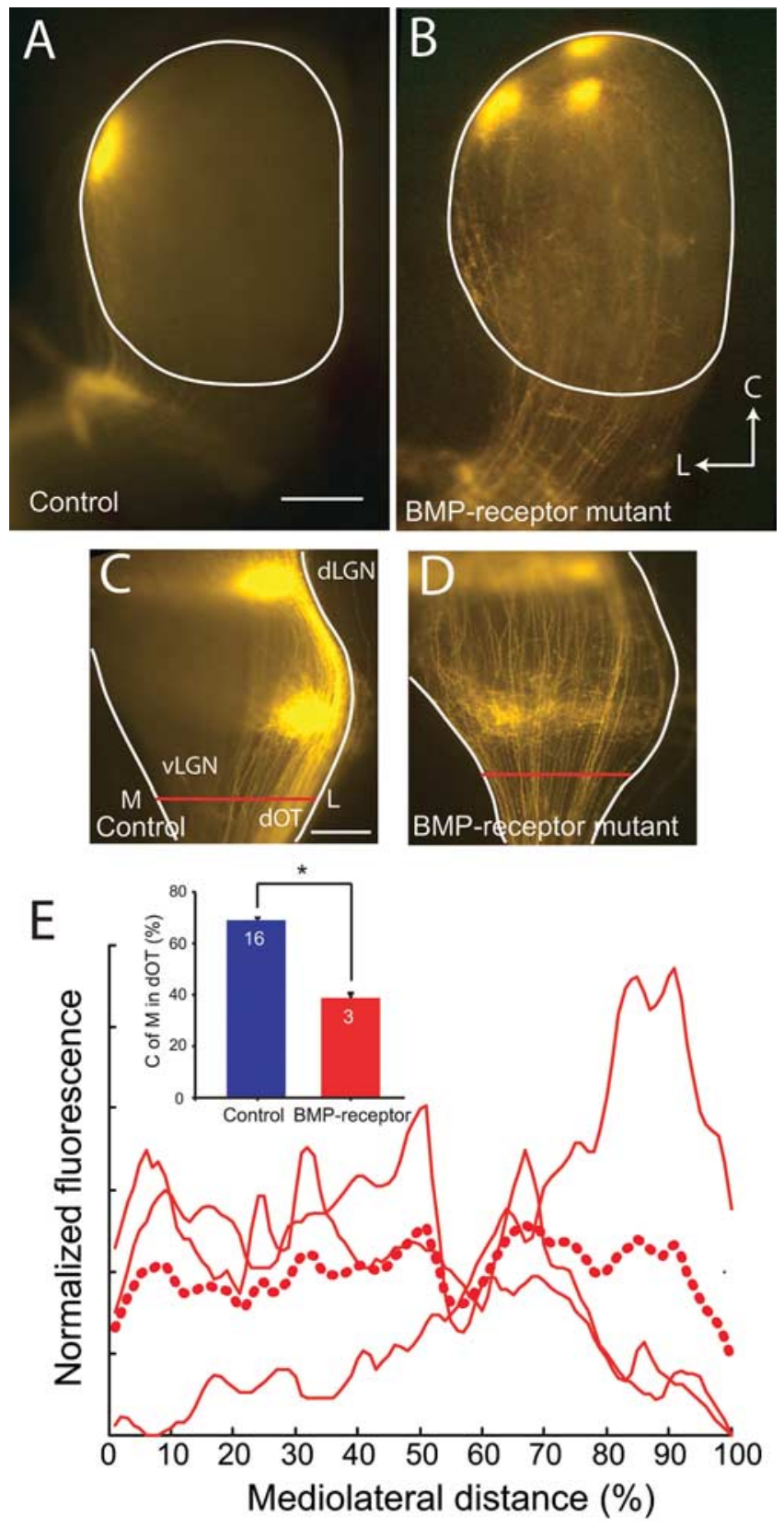

Figure 8. Axon sorting disturbed in BMP receptor mutants is similar to that in Noggin transgenics at P8. $\boldsymbol{A}$, Dorsal retinal axons form a single focal TZ in lateral SC in control mice. $\boldsymbol{B}$, In a retina lacking BMPR1a and one copy of BMPR1b (BMP receptor mutants), dorsal retinal axons form ectopic projections in addition to the normal TZ. L, Lateral; $C$, caudal. C, Dorsal axons at the dOT in control mice are segregated to the lateral $(L)$ optic tract. $D$, In the BMP receptor mutant mice, dorsal axons fail to segregate to lateral optic tract. $\boldsymbol{E}$, Distribution of dorsal RGC axons in the $\mathrm{dOT}$ of BMP receptor mutants is shown as normalized fluorescence across the width of the d0T. Individual examples are shown as solid red lines, and the average is represented as a dashed red line. Summary quantification (inset) shows the mean center of mass ( $C$ of $M$ ) of fluorescently labeled axons in the d0T for dorsal injections in WT mice and BMP receptor mutant mice. The center of mass of label at the dOT in BMP receptor mutant mice is significantly more medial (M) than that for WT mice $\left({ }^{*} p<0.001\right)$. Error bars indicate SEM. Scale bars: (in $\left.\boldsymbol{A}\right) \boldsymbol{A}, \boldsymbol{B}$, $500 \mu \mathrm{m}$; (in C) C, D, $250 \mu \mathrm{m}$.

also disturbed. This suggests that BMP signaling is necessary for ephrinB2 expression in the retina, and that high levels of BMP suppress EphB2 expression, but BMP signaling is not necessary for EphB2 expression. Moreover, the graded expression pattern of EphB2 is dependent on the graded expression of BMP in the 

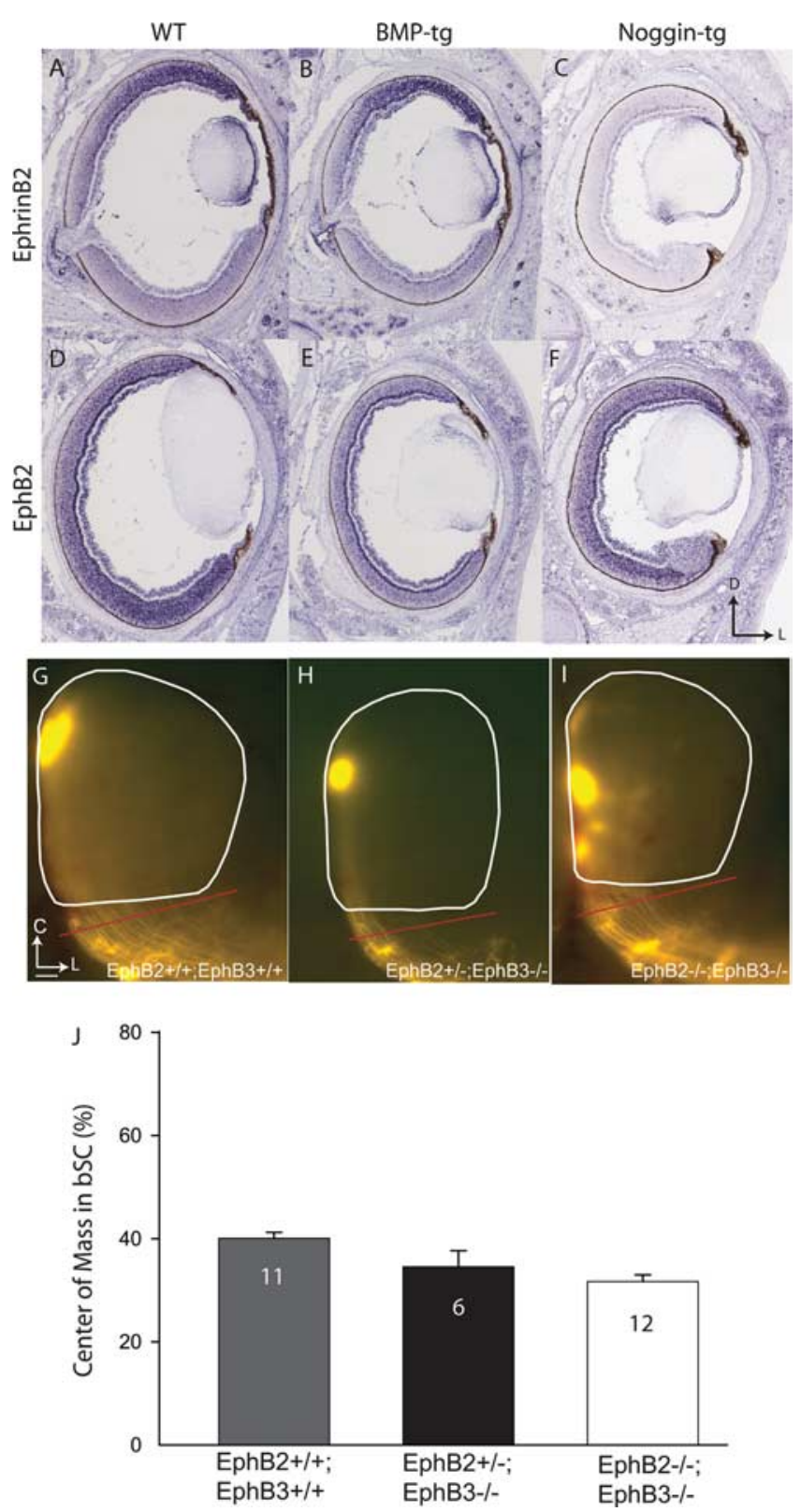

Figure 9. In situ hybridization reveals altered expression patterns of EphB2 and ephrinB2 in the retina of BMP-tg and Noggin-tg mice, but ventral axons are not missorted in EphB2/B3 mutant mice. $\boldsymbol{A}$, In WT mice, ephrinB2 is expressed in a high-dorsal to low-ventral gradient. $\boldsymbol{B}$, The ephrinB2 expression pattern is not altered in BMP-tg mice. $\boldsymbol{C}$, EphrinB2 expression is dramatically suppressed in Noggin-tg mice. D, In WT mice, EphB2 shows a high-ventral to lowdorsal expression pattern. $\boldsymbol{E}$, EphB2 expression is suppressed in BMP-tg, and no obvious gradient is present. $\boldsymbol{F}$, EphB2 expression lacks a high-ventral to low-dorsal pattern in Noggin-tg mice, although average expression levels are normal. D, Dorsal; L, lateral. G-I, At P8, relative to controls $(\boldsymbol{G})$, ventral RGC axons in EphB2 $2^{+I-} ; B 3^{-I-}(\boldsymbol{H})$ and EphB2 $2^{-I-} ; \mathrm{B} 3^{-I-}$ mice $(\boldsymbol{I})$ are not missorted in the brachium of the $S C(G, H$, red bar). $C$, Caudal. $\boldsymbol{J}$, Summary quantification of center of mass for ventral injections in the bSC of WT and EphB2/B3 mutants. The sorting of EphB2/B3 double mutants is slightly better (with a smaller center of mass) than controls. Error bars indicate SEM. Scale bar: (in G) $\mathbf{G}-\mathbf{I}, 100 \mu \mathrm{m}$.

eye. Finally, the effect of Noggin on EphB2/ephrinB2 expression observed in Noggin-tg mice is very similar to that found in BMP receptor mutant mice (Murali et al., 2005), confirming the role of $\mathrm{BMP}$ in regulating the expression of EphB2/ephrinB2 in the retina. These results are also consistent with published reports in the chick (Koshiba-Takeuchi et al., 2000; Sakuta et al., 2001; Sakuta et al., 2006) arguing for a similar role across species for an endoge- nous dorsoventral gradient of BMP in the developing eye establishing dorsoventral retinal cell fate.

\section{Pretarget sorting in bSC and dOT rely on BMP signaling}

Axons originating along the dorsoventral axis of the retina show evidence of presorting in the optic tract of the rodent soon after they exit the optic chiasm (Simon and O'Leary, 1991; Chan and Guillery, 1994; Plas et al., 2005). Molecular/chemical guidance cues downstream of BMP signaling in the retina are responsible for this pretarget sorting, because axons at the bSC and in the ascending dOT are disorganized in the BMP-tg, Noggin-tg, and BMP receptor mutants (Figs. 2-4, 8).

\section{LGN targeting depends on BMP signaling}

Retinotopic precision in the mouse LGN is difficult to assay because of the small size of the LGN relative to the SC and its convoluted anatomy. Nonetheless, we frequently observed mistargeting (ectopic spots) in the LGN that was associated with sorting errors in the ascending optic tract and the formation of ectopic spots in the SC (Figs. 7, 8). This correspondence suggests that retinotopy in the LGN is regulated by similar mechanisms as in the SC, both of which are downstream of BMP signaling in the retina.

\section{Effects of BMP signaling on nasotemporal targeting}

Dorsal axons are targeted and sorted normally in BMP-tg mice, whereas ventral axons are profoundly disturbed. In Noggin-tg mice, dorsal axons are profoundly disturbed, but even ventral axons are partially disrupted. RGC axons originating along the nasotemporal axis of the mouse retina show no evidence of sorting in the ascending optic tract (Plas et al., 2005). Thus, targeting errors along the rostral-caudal axis of the SC in the BMP-tg, Noggin-tg, and BMP receptor mutant mice are not likely attributable to sorting errors in the optic tract. Disturbing the expression of BMP or transcription factors downstream of BMP can cause changes in the expression of ephrinA2 and EphA5 (Sakuta et al., 2001, 2006; Mui et al., 2002; Liu et al., 2003) (but see Barbieri et al., 2002). This suggests that the partial sorting phenotype of ventral axons in Noggin-tg mice and the anteriorposterior targeting errors in the BMP-tg, Noggin-tg, and BMP receptor mutant mice are attributable to the effects of BMP signaling in the regulation of EphA/ephrinA expression in the retina.

\section{Pretarget sorting defects in BMP-tg mice are evident before target formation}

The retinal ganglion cell axon sorting defects observed in the BMP-tg, Noggin-tg, and BMP receptor mutant mice are clearly evident in anatomical structures en route to their targets. Moreover, these sorting defects are present in the optic tract at a developmental stage (P0-P1) when no clear target zone has established itself in the SC or LGN. Sorting in the ascending optic tract is therefore not a by-product of targeting in the LGN or SC, and may serve a necessary function in the formation of topographically accurate projections by retinal ganglion cell axons to their central targets.

In the neonatal (P2-P3) SC of BMP-tg mice, there is a high density of retinal ganglion cell axons at off-target locations relative to WT controls, even before focal target zones or ectopic spots have formed in the colliculus (Figs. 5, 6). One week later, when retinocollicular map refinement is complete (Simon and O'Leary, 1992a), ectopic spots in BMP-tg SC receive some of their axonal innervation directly from missorted axons that originate 
from the wrong mediolateral position in the brachium of the SC (Fig. 6). This suggests that the sorting of axons before they reach their target may produce a threshold density of axons necessary for activity-dependent factors to refine retinal projections into a mature topographic map (Chandrasekaran et al., 2005). Errors in direction-specific branching that occur subsequent to missorting likely also contribute to the formation of ectopic target zones in the colliculus (Hindges et al., 2002; McLaughlin et al., 2003).

\section{EphB2/B3 signaling is not responsible for pretarget sorting}

What are the mechanisms responsible for pretarget sorting of RGC axons based on their dorsoventral origin? One possibility is that axon-axon interactions between RGCs based on their expression of EphBs and ephrinBs in a countergradient may lead to sorting via contact-mediated repulsion (Marston et al., 2003; Zimmer et al., 2003). Alternatively, RGC axon-born EphB receptors may interact with ephrinB ligands expressed in specific populations of chiasmatic cells, in a manner analogous to the mechanism of ipsilateral-contralateral sorting that has recently been described at the chiasm (Nakagawa et al., 2000; Williams et al., 2003). Hypothesizing a role for EphB receptors on RGC axons is parsimonious, because they have previously been shown to play a role in target-specific branch formation in the superior colliculus (Hindges et al., 2002; McLaughlin et al., 2003). However, we did not find that pretarget sorting defects of RGC axons in EphB2/B3 mutant mice were worse than controls. If anything, we found that sorting in the mutants was marginally better than controls, which could be a by-product of EphB/ephrinB signaling in the control of axon fasciculation (Orioli et al., 1996; Chen et al., 2004), or related to the albino background of the EphB2/B3 mutant mice. Interestingly, the sorting of ventral axons in the albino (CD1) background of the EphB2/B3 mice was clearly worse than wildtype (C57BL/6) mice, suggesting that defects in the development of the retinofugal pathway known to exist in albino mice (Guillery et al., 1995; Rice et al., 1995; Marcus et al., 1996) may also affect sorting in the ascending optic track. The much stronger mapping (targeting) phenotypes in BMP-tg, Noggin-tg, and $\mathrm{BMP}$ receptor mice compared with EphB2/EphB3 receptor mutants also suggests that additional guidance mechanisms beyond EphB/ephrinB signaling in the target are crucial for mapping the dorsoventral axis of the retina.

Our experiments have ruled out EphB2/B3 receptor signaling as the mechanism by which BMP signaling regulates axon sorting in the ascending optic tract. Thus, the mechanisms regulating dorsoventral sorting in the optic tract of the mouse are at least in part distinct from those controlling target specific branching in the superior colliculus, as has been previously demonstrated in Xenopus (Chien et al., 1995). There is ample evidence for other signaling pathways playing a role in dorsoventral RGC axon guidance and targeting. Wnt-Ryk signaling is thought to mediate aspects of retinotectal mapping of dorsoventral RGC axons in the chick, but little is known of their function in the mouse (Schmitt et al., 2006). BMP signaling might also regulate heparan sulfate proteoglycan function, which is required for sorting of dorsal retinal axons in the optic tract of zebrafish and retinal axon guidance at the chiasm in mice (Inatani et al., 2003; Lee et al., 2004; Pratt et al., 2006). Cell adhesion molecules (L1) have recently been implicated in the regulation of mediolateral topography in the colliculus (Buhusi et al., 2008), and are also differentially expressed in the ascending optic tract [L1 and NCAM (Chung et al., 2004)] and are therefore potential candidates to mediate RGC pretartget sorting.

Our data show that BMPs play an important role in the estab- lishment of retinal ganglion cell fate, with strong effects along the dorsoventral axis, and more circumscribed effects along the nasotemporal axis. Disrupting BMP signaling early in eye development causes profound errors in retinal ganglion cell axon sorting in the ascending optic tract through a mechanism independent of EphB2/B3 receptors. Targeting errors caused by interfering with retinal BMP signaling are also quite severe, suggesting that mechanisms regulating sorting in the ascending optic tract and branching in the central target both contribute to the retinotopic mapping of dorsoventral RGC axons.

\section{References}

Barbieri AM, Broccoli V, Bovolenta P, Alfano G, Marchitiello A, Mocchetti C, Crippa L, Bulfone A, Marigo V, Ballabio A, Banfi S (2002) Vax2 inactivation in mouse determines alteration of the eye dorsal-ventral axis, misrouting of the optic fibres and eye coloboma. Development 129:805-813.

Birgbauer E, Cowan CA, Sretavan DW, Henkemeyer M (2000) Kinase independent function of EphB receptors in retinal axon pathfinding to the optic disc from dorsal but not ventral retina. Development 127:1231-1241.

Braisted JE, McLaughlin T, Wang HU, Friedman GC, Anderson DJ, O'Leary DD (1997) Graded and lamina-specific distributions of ligands of EphB receptor tyrosine kinases in the developing retinotectal system. Dev Biol 191:14-28.

Buhusi M, Schlatter MC, Demyanenko GP, Thresher R, Maness PF (2008) $\mathrm{L} 1$ interaction with ankyrin regulates mediolateral topography in the retinocollicular projection. J Neurosci 28:177-188.

Cang J, Niell CM, Liu X, Pfeiffenberger C, Feldheim DA, Stryker MP (2008) Selective disruption of one cartesian axis of cortical maps and receptive fields by deficiency in Ephrin-As and structured activity. Neuron 57:511-523.

Carson JP, Thaller C, Eichele G (2002) A transcriptome atlas of the mouse brain at cellular resolution. Curr Opin Neurobiol 12:562-565.

Carson JP, Ju T, Lu HC, Thaller C, Xu M, Pallas SL, Crair MC, Warren J, Chiu W, Eichele G (2005) A digital atlas to characterize the mouse brain transcriptome. PLoS Comput Biol 1:e41.

Chan SO, Guillery RW (1994) Changes in fiber order in the optic nerve and tract of rat embryos. J Comp Neurol 344:20-32.

Chandrasekaran AR, Plas DT, Gonzalez E, Crair MC (2005) Evidence for an instructive role of retinal activity in retinotopic map refinement in the superior colliculus of the mouse. J Neurosci 25:6929-6938.

Chapman DL, Garvey N, Hancock S, Alexiou M, Agulnik SI, Gibson-Brown JJ, Cebra-Thomas J, Bollag RJ, Silver LM, Papaioannou VE (1996) Expression of the T-box family genes, Tbx1-Tbx5, during early mouse development. Dev Dyn 206:379-390.

Chen ZY, Sun C, Reuhl K, Bergemann A, Henkemeyer M, Zhou R (2004) Abnormal hippocampal axon bundling in EphB receptor mutant mice. J Neurosci 24:2366-2374.

Chien CB, Cornel EM, Holt CE (1995) Absence of topography in precociously innervated tecta. Development 121:2621-2631.

Chung KY, Leung KM, Lin CC, Tam KC, Hao YL, Taylor JS, Chan SO (2004) Regionally specific expression of L1 and sialylated NCAM in the retinofugal pathway of mouse embryos. J Comp Neurol 471:482-498.

Dale JK, Vesque C, Lints TJ, Sampath TK, Furley A, Dodd J, Placzek M (1997) Cooperation of BMP7 and SHH in the induction of forebrain ventral midline cells by prechordal mesoderm. Cell 90:257-269.

De Robertis EM, Kuroda H (2004) Dorsal-ventral patterning and neural induction in Xenopus embryos. Annu Rev Cell Dev Biol 20:285-308.

Furuta Y, Hogan BL (1998) BMP4 is essential for lens induction in the mouse embryo. Genes Dev 12:3764-3775.

Graff JM (1997) Embryonic patterning: to BMP or not to BMP, that is the question. Cell 89:171-174.

Guillery RW, Mason CA, Taylor JS (1995) Developmental determinants at the mammalian optic chiasm. J Neurosci 15:4727-4737.

Henkemeyer M, Orioli D, Henderson JT, Saxton TM, Roder J, Pawson T, Klein R (1996) Nuk controls pathfinding of commissural axons in the mammalian central nervous system. Cell 86:35-46.

Hindges R, McLaughlin T, Genoud N, Henkemeyer M, O’Leary DD (2002) EphB forward signaling controls directional branch extension and ar- 
borization required for dorsal-ventral retinotopic mapping. Neuron 35:475-487.

Hung FC, Zhao S, Chen Q, Overbeek PA (2002) Retinal ablation and altered lens differentiation induced by ocular overexpression of BMP7. Vision Res 42:427-438.

Inatani M, Irie F, Plump AS, Tessier-Lavigne M, Yamaguchi Y (2003) Mammalian brain morphogenesis and midline axon guidance require heparan sulfate. Science 302:1044-1046.

Koshiba-Takeuchi K, Takeuchi JK, Matsumoto K, Momose T, Uno K, Hoepker V, Ogura K, Takahashi N, Nakamura H, Yasuda K, Ogura T (2000) Tbx5 and the retinotectum projection. Science 287:134-137.

Lee JS, von der Hardt S, Rusch MA, Stringer SE, Stickney HL, Talbot WS, Geisler R, Nüsslein-Volhard C, Selleck SB, Chien CB, Roehl H (2004) Axon sorting in the optic tract requires HSPG synthesis by ext2 (dackel) and extl3 (boxer). Neuron 44:947-960.

Liu J, Wilson S, Reh T (2003) BMP receptor $1 \mathrm{~b}$ is required for axon guidance and cell survival in the developing retina. Dev Biol 256:34-48.

Luo L, Flanagan JG (2007) Development of continuous and discrete neural maps. Neuron 56:284-300.

Mann F, Ray S, Harris W, Holt C (2002) Topographic mapping in dorsoventral axis of the Xenopus retinotectal system depends on signaling through ephrin-B ligands. Neuron 35:461-473.

Marcus RC, Wang LC, Mason CA (1996) Retinal axon divergence in the optic chiasm: midline cells are unaffected by the albino mutation. Development 122:859-868.

Marston DJ, Dickinson S, Nobes CD (2003) Rac-dependent transendocytosis of ephrinBs regulates Eph-ephrin contact repulsion. Nat Cell Biol 5:879-888.

McLaughlin T, O'Leary DD (2005) Molecular gradients and development of retinotopic maps. Annu Rev Neurosci 28:327-355.

McLaughlin T, Hindges R, Yates PA, O'Leary DD (2003) Bifunctional action of ephrin-B1 as a repellent and attractant to control bidirectional branch extension in dorsal-ventral retinotopic mapping. Development 130:2407-2418.

Mui SH, Hindges R, O'Leary DD, Lemke G, Bertuzzi S (2002) The homeodomain protein Vax2 patterns the dorsoventral and nasotemporal axes of the eye. Development 129:797-804.

Murali D, Yoshikawa S, Corrigan RR, Plas DJ, Crair MC, Oliver G, Lyons KM, Mishina Y, Furuta Y (2005) Distinct developmental programs require different levels of Bmp signaling during mouse retinal development. Development 132:913-923.

Nakagawa S, Brennan C, Johnson KG, Shewan D, Harris WA, Holt CE (2000) Ephrin-B regulates the Ipsilateral routing of retinal axons at the optic chiasm. Neuron 25:599-610.

Orioli D, Henkemeyer M, Lemke G, Klein R, Pawson T (1996) Sek4 and Nuk receptors cooperate in guidance of commissural axons and in palate formation. EMBO J 15:6035-6049.
Overbeek PA, Chepelinsky AB, Khillan JS, Piatigorsky J, Westphal H (1985) Lens-specific expression and developmental regulation of the bacterial chloramphenicol acetyltransferase gene driven by the murine alpha A-crystallin promoter in transgenic mice. Proc Natl Acad Sci U S A 82:7815-7819.

Plas DT, Lopez JE, Crair MC (2005) Pretarget sorting of retinocollicular axons in the mouse. J Comp Neurol 491:305-319.

Pratt T, Conway CD, Tian NM, Price DJ, Mason JO (2006) Heparan sulphation patterns generated by specific heparan sulfotransferase enzymes direct distinct aspects of retinal axon guidance at the optic chiasm. J Neurosci 26:6911-6923.

Rice DS, Williams RW, Goldowitz D (1995) Genetic control of retinal projections in inbred strains of albino mice. J Comp Neurol 354:459-469.

Sakuta H, Suzuki R, Takahashi H, Kato A, Shintani T, Iemura Si, Yamamoto TS, Ueno N, Noda M (2001) Ventroptin: a BMP-4 antagonist expressed in a double-gradient pattern in the retina. Science 293:111-115.

Sakuta H, Takahashi H, Shintani T, Etani K, Aoshima A, Noda M (2006) Role of bone morphogenic protein 2 in retinal patterning and retinotectal projection. J Neurosci 26:10868-10878.

Schmitt AM, Shi J, Wolf AM, Lu CC, King LA, Zou Y (2006) Wnt-Ryk signalling mediates medial-lateral retinotectal topographic mapping. $\mathrm{Na}-$ ture 439:31-37.

Simon DK, O'Leary DD (1991) Relationship of retinotopic ordering of axons in the optic pathway to the formation of visual maps in central targets. J Comp Neurol 307:393-404.

Simon DK, O'Leary DD (1992a) Development of topographic order in the mammalian retinocollicular projection. J Neurosci 12:1212-1232.

Simon DK, O'Leary DD (1992b) Influence of position along the mediallateral axis of the superior colliculus on the topographic targeting and survival of retinal axons. Brain Res Dev Brain Res 69:167-172.

Sperry RW (1963) Chemoaffinity in the orderly growth of nerve fiber patterns and connections. Proc Natl Acad Sci U S A 50:703-710.

Visel A, Thaller C, Eichele G (2004) GenePaint.org: an atlas of gene expression patterns in the mouse embryo. Nucleic Acids Res 32(Database issue):D552-D556.

Williams SE, Mann F, Erskine L, Sakurai T, Wei S, Rossi DJ, Gale NW, Holt CE, Mason CA, Henkemeyer M (2003) Ephrin-B2 and EphB1 mediate retinal axon divergence at the optic chiasm. Neuron 39:919-935.

Yaylaoglu MB, Titmus A, Visel A, Alvarez-Bolado G, Thaller C, Eichele G (2005) Comprehensive expression atlas of fibroblast growth factors and their receptors generated by a novel robotic in situ hybridization platform. Dev Dyn 234:371-386.

Zhao S, Chen Q, Hung FC, Overbeek PA (2002) BMP signaling is required for development of the ciliary body. Development 129:4435-4442.

Zimmer M, Palmer A, Köhler J, Klein R (2003) EphB-ephrinB bidirectional endocytosis terminates adhesion allowing contact mediated repulsion. Nat Cell Biol 5:869-878. 